\title{
The role of corporates in creating sustainable Olympic legacies
}

\begin{abstract}
The Olympic Games is a major stimulus for increased tourism. In recent years there have been greater calls for this and other mega-events to leave sustainable positive legacies for the host city, partly to offset the massive cost of hosting. To date, little consideration has been afforded to the role corporates might play in contributing to event legacies. This gap is compounded by the lack of research examining stakeholder engagement in legacy planning more generally. This paper adopts Holmes, Hughes, Mair and Carlsen's (2015) sustainable event legacy timeline to conceptualise how corporates through the corporate social responsibility (CSR) initiatives of sponsorship and employee volunteering can engage across the Olympic event planning cycle to generate volunteering legacies. Drawing upon a comparative study of the Sydney 2000 and London 2012 Olympic Games, tentative evidence of corporate engagement was noted but for the most part it was fragmented and CSR initiatives primarily focused on the immediate planning and delivery stages of the event cycle. The paper advances new knowledge of how volunteering legacies can be generated through the best practice engagement of corporates as key stakeholders involved in legacy planning and governance across the Olympic planning cycle.
\end{abstract}

Key words: Corporate social responsibility; Olympic Games; Volunteers; Event legacies; Volunteering legacies 


\section{Introduction}

This paper examines the role of corporates in contributing to sustainable mega-event legacies in respect of the corporate social responsibility (CSR) initiatives of corporate sponsorship and employee volunteering. As the contextual focus of the current study, the Olympic Games is a global sports event and tourist attraction, and like other mega-events, governments seek to leverage these spectacles for future tourism development (Carey, Mason \& Misener, 2011). A number of forces have coalesced to ensure that Olympic and mega-event hosting must be more sustainable in terms of impact than ever before. These include the push to ensure ongoing benefits from event hosting in the form of tangible and intangible legacies (IOC, 2012), together with acceptance in the wider business environment for firms to give back to society and communities through CSR initiatives (Kotler \& Lee, 2004). Consideration of Olympic legacies is still a relatively recent phenomenon within the history of the Olympic movement with the International Olympic Committee (IOC) designating legacies as part of the Olympic Charter in 2003 (IOC, 2007). Leopkey and Parent (2012) note adoption of the concept as early as the 1980s. Research investigating legacies is likewise in an emergent phase with Dickson, Benson and Blackman (2011) noting the lack of an international research agenda for legacy research, with limited studies examining amongst key stakeholders whose responsibility it is for delivering sustainable legacies (Leopkey \& Parent, 2012, 2017).

For the purposes of the current study, a corporate is defined as a large company with a profit driven motive, although the terminology of 'corporates' or 'companies' is rarely specified in the CSR literature. CSR is an established practice in modern business, recognised as gaining ground following its early roots in corporate philanthropy (Carey et al., 2011). CSR involves "a commitment to improve community well-being through discretionary business practices 
and contributions of corporate resources" (Kotler \& Lee, 2004, p. 3), although definitions of the concept are contested (Sheth \& Babiak, 2009).

Building on growing research interest in understanding CSR in sport event and sustainable tourism settings, this study addresses two key knowledge gaps: 1) in a first, it links the CSR concepts of event sponsorship and employee volunteering to event legacy planning 2) in doing so, a framework whereby corporates through these CSR initiatives contribute to a sustainable legacy for volunteering, pre- and post-event is proposed, informed by Holmes, Hughes, Mair and Carlsen's (2015) sustainable event legacy timeline. Using this framework, the study positions corporates in the previously unimagined role of a key stakeholder group involved in the generation of volunteering legacies and further identifies realised and potential areas for this cohort to capitalise upon their CSR efforts. Drawing on primary and secondary data sources, the study populates the framework to discern to what extent and how corporates were involved from bid to post-event legacy delivery at the Sydney 2000 and London 2012 Olympic Games. Underpinning the study, the paper now turns to review the limited literature on CSR as it relates to event sponsorship and employee volunteering, followed by discussion of the growing body of literature on mega-event legacies and stakeholder engagement in legacy management.

\section{CSR and sports events}

CSR has evolved to become an essential business function in the $21^{\text {st }}$ century. In general, studies have shown that companies promoting their CSR activities are rewarded by a range of stakeholders, including their customers (Sen \& Bhattacharya, 2001). Whilst generally viewed as positive and something an organisation chooses to voluntarily do (Dowling, Robinson \& 
Washington, 2013), the motives of organisations for engaging in CSR initiatives has been criticised as self-interested (Basu \& Palazzo, 2008). Companies have also faced critical commentary about their track record of implementing effective CSR activities (Bhattacharya, Korschun \& Sen, 2009). Despite these criticisms, CSR continues to be one of the most noteworthy movements affecting corporate practice in recent decades (Walker, Heere, Parent \& Drane, 2010).

Acknowledging these criticisms, this paper draws on research examining CSR initiatives in relation to sports and sports events, contextualised to the Olympic focus of the current study. Research dedicated to these settings is a newer phenomenon compared to the broader body of CSR studies. Indeed, the links between CSR and sport event sponsorship (Close Scheinbaum \& Lacey, 2015) and CSR and employee volunteering (Plewa, Conduit, Quester \& Johnson, 2015) have only been recently made and to our knowledge there is no research that has explicitly studied both as complementary CSR initiatives in relation to sporting events. As such, the literature related to each initiative will be discussed separately and commonalities drawn, where possible.

In proposing a conceptual model linking sport sponsorship effectiveness with the sponsors' CSR commitment, Plewa and Quester (2011) noted the paucity of studies testing the effectiveness of sports sponsorship as a form of CSR. Sponsorship is generally held to be a business arrangement between an organisation (the sponsor) supplying cash and/or in-kind resources and an event or organisation, which offers in return particular rights, often exclusive, which can be used to the competitive advantage of the sponsor (Plewa \& Quester, 2011). Of the limited studies that have empirically tested the effects of linking CSR initiatives to sponsorship, a raft of positive benefits for the sponsor have been demonstrated. Uhrich, 
Koenigstorfer and Groeppel-Klein (2014) found positive effects on consumer perceptions for brands with moderately low congruity to the sponsored event. In other words, for events where there was not a natural, assumed fit between the sponsor and the event, CSR initiatives were able to bridge the gap and enhance consumer's perceptions of the sponsor. Evidence also supports that when sponsors are viewed as being socially responsible, customers are more positively inclined to the sponsor and its products in terms of commitment and purchase intentions (Lacey, Close \& Finney, 2010).

Plewa, Carillat, Mazodier and Quester (2016) argued that sponsors can benefit from partnering with sports organisations that are proactive with their own CSR initiatives. The study found that sponsors were indirectly attributed with altruistic motives as a result of sponsoring sports organisations that were closely engaged with their community either as sponsors or through community outreach programmes. Coining the terminology of 'event social responsibility', Close Scheinbaum and Lacey (2015) also found evidence of attribution effects. If attendees assessed a community event as being socially responsible, they were more willing to purchase the products of its sponsors. Adopting a qualitative approach, Batty, Cuskelly and Toohey (2016) noted the uptake of CSR sponsorship in community sport event settings and concluded that such sponsorships can be used by sponsors, including food and beverage sponsors, to circumvent negative perceptions of the harmful effects of their products. Of importance to the current study, Plewa and Quester (2011) contend that sponsorship "faces less consumer resistance and scepticism, particularly when focusing on community-based properties or when relying on volunteering programmes" (p. 303).

In terms of Olympic sponsorship and CSR studies, Kim (2013) highlights how sponsors at the London 2012 Games provided examples of CSR through a range of initiatives. A cited 
example was Coca-Cola's partnering over three years with a UK charity to offer youth sports training in areas with inadequate sports facilities. In total, 11 key sponsors signed eight-year contracts worth 1 billion US dollars to support the London Games and promote their CSR credentials (Kim, 2013). To doing so, research has indicated that sponsorship of the 2012 Games benefited sponsoring organisations with their employees feeling a sense of pride in their employer and viewing them as socially responsible (Edwards, 2016). Dowling et al. (2013) examined the leveraging of CSR partnerships from a scheme launched in 2007 and brokered by the British National Olympic Committee, matching FTSE-100 companies with national sport governing bodies to offer them in-kind operational support and advice in the lead up to London 2012. The authors contend this approach, involving the short-term involvement and secondment of the corporates' human resources, offered a more meaningful way to engage with the Games, without the restrictions and considerable expense of Olympic sponsorship. They further suggest in concluding their study that despite the inherent attraction of sport in the lead up to mega-events "there may be better times than others for sport organisations to seek CSR and partnership arrangements - a theoretical consideration that has yet to receive any scholarly attention" (Dowling et al., 2013, p. 288).

Dowling et al.'s (2013) study hints at the involvement of employee volunteering in CSR initiatives, however, there are limited studies linking or empirically testing the relationships between both concepts (Haski-Leventhal, Meijs \& Hustinx, 2009; Plewa et al., 2015). For the purposes of this study, employee/corporate volunteering is defined as companies encouraging their "employees to give time and expertise as volunteers, and volunteer activities can be undertaken within or outside the employee's official workload and time" (Haski-Leventhal et al., 2009, p. 148). The limited available evidence suggests that employee volunteering is linked to social capital creation particularly when social interactions between the key actors 
are facilitated and maintained and existing networks utilised in this process (Muthuri, Matten \& Moon, 2009). Plewa et al. (2015), in a rare empirical study, found that customer's familiarity with a company's employee volunteering initiatives was linked to positive assessments that the company was socially responsible, with beneficial implications for corporates in promoting such programmes to external stakeholders.

Having reviewed the extant literature in reference to sport event sponsorship and employee volunteering as distinct CSR initiatives, the importance of strong partnerships with stakeholders (Bhattacharya et al., 2009; Sheth \& Babiak, 2010) over a sustained period (Dowling et al., 2013; Kim, 2013) has been highlighted as underpinning the success of such initiatives. The same key ingredients are often postulated in relation to promoting sustainable event legacy planning but rarely studied for confirmation. Indeed, there are no studies examining employee volunteering and event sponsorship as CSR initiatives in combination and additionally, there are no studies investigating their potential impact, if any, on legacy realisation, although it should be noted that Carey et al. (2011) and Watt (2010) in their CSR studies have referenced legacy in passing. We argue that corporate involvement in legacy generation offers a useful extension of the traditional Games time association of corporates with mega-events addressing Dowling et al.'s (2013) call for research on the temporal considerations of CSR partnerships, with the potential to integrate the CSR initiatives of corporates across the entire event cycle, promoting a sustainable legacy for volunteering in the process.

\section{Mega-event volunteer legacies and stakeholder engagement}


The literature on volunteering legacies is positioned relative to the broader legacy literature. Several authors have noted the predominance of economic and tourism focused studies (Preuss, 2007), together with sporting and local infrastructure legacies as particular foci for early legacy research (Leopkey \& Parent, 2012). In contrast, there are limited studies evaluating the social as opposed to tangible legacies of mega-events (Dickson, Benson \& Blackman, 2011; Minnaert, 2012). Collectively, there is a positive tone to these studies, with limited attention paid to the negative consequences of event legacies (Cashman, 2006).

Research interest in event volunteering legacies began with studies examining how to encourage volunteers to 'bounceback' and volunteer again at the same event (B. Coyne \& Coyne, 2001; Elstad, 1996). Studies have progressed to examine how event volunteer programmes can lead to future volunteering in host cities as part of community or social legacies (Auld, Cuskelly \& Harrington, 2009; Doherty, 2009) and the legacy potential for volunteering to produce broader social inclusion outcomes (Minneart, 2012; Nichols \& Ralston, 2011).

The literature on volunteering legacies and legacy more broadly is largely silent on the planning aspects and the relationships required between various stakeholders, including corporates, to create sustainable legacies (Leopkey \& Parent, 2012, 2017). A study by Benson Dickson, Terwiel and Blackman (2014) of the Vancouver 2010 Olympic and Paralympic Winter Games highlighted the importance of a more proactive relationship between the Games organising committee and community groups in terms of planning for a legacy of host city volunteering. Benson et al. (2014) specifically focused on volunteer training as a legacy opportunity and argued that the volunteer legacy potential from the Vancouver Winter 
Olympic Games would have been augmented by improved communication between the organising committee and community groups during the event planning stage.

It is generally held that planning for positive and sustainable Olympic legacies should take place before the event, involving all relevant stakeholders including those who will be affected and those who will benefit (IOC, 2012). Indeed, stakeholder engagement was Ritchie's (2000, p. 159) “most critical” recommendation for effective mega-event legacy planning. There are suggestions however that this engagement does not always occur. In one of the few studies to examine social legacies over time, Minneart (2012) investigated the noninfrastructural impacts on socially excluded groups of seven Summer and Winter Olympic Games spanning from Atlanta (1996) through to Beijing (2008). Of the Games studied, in respect of their various initiatives for engaging these target groups, Minneart noted little evidence of engagement with existing stakeholder networks. In light of tentative evidence, Leopkey and Parent (2012, p. 938) support that research is needed to establish "who should take on the lead role and to what degree other Games stakeholders have influence in the strategic planning, decision making and post-Games sustainability of the Games benefits".

Of the event legacy planning frameworks conceptualised to date, these typically focus on different kinds of legacies including infrastructure, economic, tourism, social and so on (Dickson et al., 2011). Preuss (2007) offers a temporal model for event legacy planning however it moves directly from the event to post-event period. This is problematic because researchers (Benson et al., 2014; Dickson et al., 2011; Nichols \& Ralston, 2011) have noted that the post-event phase of any mega-event is never straightforward as organising bodies shut down their operations and these need to be transferred to legacy bodies who are rarely the same organisations. Additionally, many events report a slump immediately after the event 
(Cashman, 2006; Nakamura \& Susuki, 2017). The inclusion of a transition phase between the event and implementing the event legacy is an important feature of Holmes et al.'s (2015) legacy timeline, which details what key actions need to take place at each phase of the timeline to assist sustainable event legacy planning.

In addressing Dickson et al.’s (2011, p. 292) call for “substantive empirical research in respect of pre, during and, in particular, post-event" legacies, the timeline identifies five stages in the event lifecycle (see Figure 1). It was informed by the extant event legacy literature drawn from multiple disciplinary backgrounds including economics, geography and sociology (Flyvbjerg \& Stewart, 2012; Minneart, 2012; Preuss, 2007). In a first, the current study will use the timeline as a framing mechanism to examine the extent to which corporates through their CSR initiatives of sponsorship and employee volunteering can contribute to a sustainable legacy for volunteering, pre- and post-event. In doing so, the study addresses research gaps relating to our temporal understanding of the optimal timing for corporates and other stakeholders to engage in CSR initiatives across the mega-event cycle (Dowling et al., 2013) and understanding of the mechanisms and actors involved in legacy management (Leopkey \& Parent, 2012, 2017) beyond the remit of organising committees. Data collected from two case study Olympic Games, Sydney 2000 and London 2012, allows for insight as to missed, realised and potential opportunities for corporates to engage across the Olympic planning cycle to generate volunteering legacies.

---Insert Figure 1 about here---

\section{Method}


To investigate the role of corporates in contributing to ongoing mega-event legacies through their CSR initiatives, a case study design was adopted to study two summer Olympic Games. This approach was guided by Minnaert's (2012) study which, like the current study, offered a comparative perspective over an extended period, supported by secondary and primary data sources. The study was additionally guided by the pragmatist paradigm, where the primary importance for the researcher is the purpose and nature of the research (Creswell \& Plano Clark, 2007) and the positivist-interpretivist dichotomy is rejected. Pragmatism is the paradigm most commonly associated with mixed methods research (Tashakkori \& Teddlie, 2003). As Pragmatists are concerned with investigating complex, real-world problems using multiple forms of data, the case studies employed a mixture of data sources and data types to provide a complete picture of the phenomenon under study (Yin, 2014). Recognising that volunteering and other legacies may take considerable time after the event to assess, the study compared the recent example of London 2012 (where the Games had taken place four years before data collection) with Sydney 2000 (where there were sixteen years of potential legacy to reflect upon). While the two events took place during different social and economic times and in different geographic locations, they also shared contextual similarities with both Australia and the United Kingdom (UK) being liberal democracies with strong volunteering cultures (Musick \& Wilson, 2007). Importantly for their selection as case studies, the Sydney Games took place in the pre-legacy era of the Olympics. In contrast, as will be discussed, London's bid for and hosting of the 2012 Games was strongly informed by the attention more latterly afforded to legacy.

The study was designed in two phases. Stage One involved a comprehensive review of secondary data to underpin the background of each case. This included academic research, policy documents, media reports, and other material produced by relevant organisations. 
Google and Google Scholar were used as the primary search engines to identify relevant material using the search terms: 'volunteer legacy', 'Olympic volunteer programme', 'employee volunteering', 'corporate volunteering' and 'corporate sponsorship', aligned to the relevant case study Games. In terms of the Sydney search, generally the first 15 to 20 web pages were reviewed for each search item (typically containing 10 links per page). The Sydney case was also supplemented by archival material sourced from The Centre for Volunteering New South Wales, the State's peak volunteering body, which had a pivotal role in advising the Sydney Games organisers in relation to their volunteering programme. In the case of London, given the greater prominence afforded to legacy, 25 web pages were reviewed using the 'volunteer legacy' term, with between five and 10 web pages reviewed as checks of the additional search terms. All secondary data for this case was obtained online. For both cases, only materials deemed relevant to the study were retained for analysis and duplicates excluded throughout the process.

Stage Two involved semi-structured interviews with representatives from relevant stakeholder groups with a vested interest in planning the Games volunteer programme and fostering a legacy for volunteering, namely, representatives from the Organising Committee for the Olympic Games (OCOG); sport governing bodies; community organisations; policy-makers and government representatives and official legacy bodies; key staff at peak bodies for the voluntary sector and volunteer resource centres; and other stakeholders.

Interview participants were recruited purposively (Cresswell, 2013) and were identified initially through the desk research undertaken in Stage One and in discussion with the national volunteering peak bodies in the UK and Australia who connected the researchers with prospective key informants. Initial participants were asked to provide recommendations 
for further interviewees using the snowballing approach (Noy, 2008). As part of a wider study, participants were asked questions designed to reveal their extent of involvement in the planning and delivery of the Games volunteer programme and volunteer legacy; and what, if any, volunteer legacy had the Games contributed to the host city. Insights as to the role of corporates as sponsors and suppliers of volunteer talent are discussed in the current paper.

Twenty-seven semi-structured interviews were conducted over a seven-month period from November 2015 to April 2016. Interviewees were either interviewed face-to-face at a location of their choosing or via Skype if located at some distance to the researchers. The interviews were generally of between 45 minutes to one hour in duration. Table 1 details the anonymised profile of the respondents (R1-R27), with the various target stakeholder groups for the research well-represented. The informants were able to provide expert input as many had senior roles in relation to the case study Games. In addition, the consistency of their responses enabled theoretical saturation to be reached (Lincoln \& Guba, 1985), whereby no new insights were likely to emerge from the conduct of additional interviews.

--- Insert Table 1 about here ---

The interviews were recorded, transcribed and analysed thematically using qualitative template analysis (King, 2004). This form of analysis involves the use of an initial coding template made up of key themes from a sample of the interviews, which is further expanded and refined in an iterative coding process involving the full set of interviews (King, 2004). The initial coding template was created using a preliminary list of themes extracted from the research questions and interviewers' notes. Further refinements were made after the full set of interviews were coded. For example, one of the main themes ,"general positive impacts", 
initially consisted of four codes related to raising the profile of volunteering, making volunteering attractive, providing a positive spin on the Games and unifying the country. A fifth was added upon detailed coding, related to improvement of volunteer practices in the wider community. The coded data was distributed to the research team for comment over several iterations until agreement was reached on the final coding template. This was subsequently interrogated relative to Holmes et al.'s (2015) sustainable legacy timeline and used to frame the results.

The study limitations must be noted to situate its relative contribution. The nature of the study as a qualitative investigation means that the findings cannot be generalised beyond the two cases studied but lessons can be learnt for future Olympic Games. The cultural and political contexts of these two cases, may not easily translate to other Olympic Games and megaevents.

Identifying interview respondents after events can sometimes lead to a focus on ‘establishment figures' (Cho \& Bairner, 2012). Given our interview respondents were senior figures involved with both case study Games, there may have been some reluctance to comment on negative, perhaps unrealised aspects of legacy, particularly in relation to the more recent case of London. In her multi-Games study, Minnaert (2012) found it harder to source respondents for the earlier Games (the earliest of which occurred a decade before the commencement of her data collection). She also questioned the validity of responses, citing the difficulties of either insufficient or too much time having passed to make meaningful judgements. We acknowledge these issues too may call into question our findings. 


\section{Findings}

The extent of corporate sponsorship and employee volunteering in pursuit of volunteering legacies is identified and conceptualised using Holmes et al.'s (2015) sustainable legacy timeline of bidding, planning, the event, transition, and legacy. Direct quotations from the secondary analysis and key informant interviews are used to support the findings.

\section{Bidding}

The sustainable legacy timeline emphasises the importance of beginning legacy plans at the bidding stage (Holmes et al., 2015). However, in reality, the case study findings indicated that there were neither legacies articulated for volunteering, nor any articulated vision for corporate involvement in relation to the Sydney and London Games at the bidding stage. Legacy was not a feature of Olympic bids in the early 1990s; not one of the 23 themes contained in the bid manual for the 2000 Games (IOC, 1992) related to legacy. As such, there was no requirement for the Sydney 2000 bid to plan for a legacy that may have facilitated corporate involvement. In contrast, 'Olympic Games Concept and Legacy' was 'Theme 1' of the 2012 Candidature Procedure and Questionnaire, where bids were required to address visions of legacy for the host city and region and detail how Games hosting would complement the host city's long-term planning strategy (IOC, 2004). In light of this prominence given to legacy, volunteering was not explicitly referred to in Theme 1 of London's candidature file, and whilst a legacy for sport, the community, the environment and the economy were articulated, reference to volunteering in support of these efforts was not mentioned (London 2012 Ltd., 2004). 
Whilst it may not have occurred in the two cases studied, there is scope to articulate a clear legacy vision for volunteering involving corporate engagement and commitments based on the long-term nature of corporate sponsor relations associated with the Games. For example, in the IOC evaluation report of the London 2012 bid, it was noted that contributions from the IOC and The Olympic Partner (TOP) sponsorship programme would amount to $36 \%$ of total Games revenue (IOC, 2005), some of which could have been allocated upfront to legacy planning.

\section{Planning}

According to the ideal of Holmes et al.'s (2015) timeline, the event planning phase is when legacy funds must be either spent or committed. In the case of the Olympic Games, there are seven years between a successful bid and the actual hosting. While legacy was neither a requirement nor focus of the Sydney Games, the official evaluation report does mention legacy several times, primarily in relation to the venues and sporting facilities. A volunteer legacy is mentioned only once, with the report stating that "...the Olympic Games will have a positive and long-lasting impact on the volunteer movement in Australia. Many people were volunteering for the first time, and it is hoped that many will continue to be involved in volunteering" (Sydney Organising Committee for the Olympic Games [SOCOG], 2001, p. 202). This suggests that there was no specific planning for a volunteer legacy, rather it was expected that the Games volunteers themselves would create a legacy independently by continuing to volunteer elsewhere. This was confirmed by an interview participant:

"We didn't have any funding to carry the legacy forward and actually neither did they, because as soon as the Olympic Games were over everything at SOCOG in relation to the volunteering shut down. So there wasn't a legacy plan". [R26] 
At the planning stage however there was some anecdotal evidence of corporate involvement in Games time planning for the volunteer programme. SOCOG established a Volunteer 2000 Advisory Committee in November 1997, which included stakeholders from voluntary groups including Rotary, the Lions Club, the YMCA and the New South Wales Rural Fire Service. Anecdotally, several members of this group additionally had senior corporate roles which appear to have laid the groundwork to facilitate the realised employee volunteering legacies of Sydney 2000 discussed later in the paper. This group met every three to four months but disbanded shortly after the conclusion of the Games, having no extended impact into the legacy phase, despite appearing to operate as a successful stakeholder engagement model.

For the London Games, key informants also questioned the extent to which a legacy for volunteering was planned for and resourced:

\footnotetext{
"But there never seemed to be clear thoughts on what the legacy was for volunteering in this area and what it was funded and what the sort of evaluation process of that was afterwards as well. So it seemed a little vague to be perfectly honest”. [R4]

“My experience and reflections on London is that if we're serious about legacy we've got to have an organisation or a body of people that are primarily or exclusively focused on legacy rather than worrying about delivery issues”. [R6]
}

For the London Games, as planning progressed, the UK Government articulated its legacy focus on making the UK a leading sporting nation; transforming East London, inspiring young people; establishing Olympic Park as a blueprint for sustainable living; and 
demonstrating the inclusiveness and visitability of London for residents and visitors alike (Department of Culture, Media and Sport [DCMS], 2008). Subsequent legacy plans, following a change of Government in 2010, focused on the promotion of sport participation; economic growth; promotion of community engagement and participation; and urban regeneration (DCMS, 2010). Specific references to volunteering emerged later, and LOCOG progress reports indicated that the Games would shape "a new culture of volunteering across the UK" (LOCOG, 2012a, p. 34).

Pre-Games policy documents and commissioned reports also highlighted the importance of "harnessing the volunteer programme alongside employment initiatives to enable local people (particularly hard-to-reach groups) to get involved in the Games, with a view to creating sustainable skills and employment in the long-term" (Experian, 2006, p. 3; see also DCMS, 2007). One of the main vehicles for doing so was the Personal Best programme, which ran from 2006-2011 offering the long-term unemployed and other disadvantaged groups the opportunity to gain a vocational qualification, with the incentive that upon successful completion, they had the opportunity to interview for a role in the Games time volunteering programme, the Games Makers (Nichols, 2012).

At the start of 2012, close to 5,000 people had completed the training (Bashir, 2012) and a post-Games report suggested "more than 1,100 Personal Best graduates were interviewed and we believe that the vast majority of these became Games Makers" (LOCOG, 2012b, p. 42). Nichols (2012) details one instance of corporate involvement in the programme as a CSR initiative, with BT providing Personal Best graduates with guided support to complete their Games Maker application forms. While positive, similar to the CSR partnership scheme Dowling et al., (2013) documented, there was further scope for corporates to become involved 
in this 'pre-volunteer programme' (Nichols, 2012), as sponsors or through the provision of employee volunteers as mentors to the participants. Such involvement may have delivered a sustained 'pre-event legacy' of volunteering. As an opportunity missed, public funding for the programme ceased in 2010, well before the 2012 Games commenced (Nichols, 2012).

In an Olympic first, proudly heralded by LOCOG, the London Games were pioneering in extending corporate sponsorship to the volunteer programme (LOCOG, 2013). McDonald's, a long-standing Olympic sponsor since 1968, was a Presenting Partner to the 2012 Games and facilitated development of the volunteer training package and offered the training in conjunction with LOCOG. Their logo was prominently displayed in the Games Maker training manual, together with a conspicuous congratulatory note from the CEO of McDonald's UK Division stating "This is a once-in-a-lifetime opportunity and as a Presenting Partner for the London 2012 Games Maker programme we want to thank you for your commitment so far. You will do so much to make London 2012 a success and we will be supporting you every step of the way to deliver a memorable Games” (LOCOG, 2011, p. 3). The involvement of McDonald's in the programme received criticism as corporatising the volunteer programme, a claim refuted by LOCOG (Kumar, 2012).

\section{The event}

In the event delivery phase, Holmes et al. (2015) consider legacy efforts are temporarily put on hold, with the focus on event delivery. Corporates in this phase are well positioned to facilitate and promote Games time employee volunteering efforts and leverage off Olympic sponsorships to full effect, maximising the collective buzz felt in the host city. 
In the case of the Sydney Games, the volunteer programme - GamesForce 2000 - was widely recognised as one of its success stories (SOCOG, 2001). Of the approximately 45,000 volunteers engaged across the Olympics and Paralympics, a number were employee volunteers, including a prominent example of 400 employees from Australian bank, Westpac. The official marketing report of the 2000 Games noted "heralded as one of the greatest successes of Sydney 2000, or any Olympic Games in history, the Volunteer 2000 programme was supported by Olympic partners who helped to increase awareness of the programme, to build the spirit of volunteerism and to provide necessities to the corps more of than 45,000 volunteers" (IOC, 2001, p. 62).

The London Games, unsurprisingly given the continued growth of the Olympics, involved a larger cohort of official volunteers. The commemorative book records that 70,000 Games Makers worked across the Olympic and Paralympic Games; these were selected from 250,000 applicants (LOCOG, 2012c), of which 40\% were inspired to volunteer for the first time (LOCOG, 2013). There were again examples of employee volunteers sourced from corporate sponsors supporting the Olympics and Paralympics, including 1,100 Cadbury employees volunteering at the Olympics (Cunliffe, 2012) and employees of parent company Kraft Foods also involved in Paralympic volunteering (Tomlinson, 2012).

In addition to sponsorship of the Games Makers programme by McDonald's, additional corporate support for volunteering was provided by Atos, a business technology supplier, that supported the online volunteer portal, and BMW, which provided adapted vehicles that facilitated volunteering opportunities for those with disabilities (IOC, 2012c). Cadbury was also acknowledged in the Games Makers training manual as the official treat provider of the Olympics (LOCOG, 2011). 
Leveraging off their sponsorship of the Games Makers programme, McDonald's engaged in a concerted campaign to promote their involvement with the programme and the Games.

Games Makers featured prominently at all stages of the 'We All Make The Games' campaign, launched two weeks before London 2012 commenced (Altin, Redford \& Webster, 2013). Advertisements were placed by McDonald's in the official Games programmes celebrating the Games Makers and they also sponsored newspaper advertising features in The Times, one showcasing a day in the life of a Games Maker and another, as a souvenir edition at the close of the Games provided to all Games Makers. This coverage, together with the widespread lauding of the Games Makers efforts, no doubt raised the profile of volunteering in the host city, as the following key informant quote suggests:

"Having worked in the volunteering space for the best part of 25 years I don't think we'd ever seen volunteering so talked about, such front page news as we did during the Games itself $[\ldots]$ There was a constant stream of good news stories about volunteering and the role it was playing, both in terms of the delivery at the Games but also in terms of just the feel good factor, making the country feel good about itself". [R6]

\section{Transition}

In the transition phase when legacy plans need to be implemented (Holmes et al., 2015), corporates can look to capitalise on the euphoria and goodwill of the Games in promoting a culture of continued employee volunteering. 
In the case of Sydney, championing a volunteer legacy was taken up by the local voluntary sector and while the substantial growth in employee volunteering since 2000 has been traced back to the event (Brettell, 2001); this was not a strategic outcome. Returning to the example of Westpac, the involvement of its employee volunteers was reported in the official marketing report of the Games (IOC, 2001) and in Westpac's first social impact report released in 2002. Westpac evidenced its continuing commitment to employee volunteering noting "around 60 per cent of our employees are involved in their local community in fund raising or volunteering work" (Westpac, 2002, p. 26).

Interestingly, in the official marketing report of the 2012 London Games (LOCOG, 2012c), while mention was made of the various Games Maker related sponsorships by McDonald's, Atos and BMW, no mention was made of any sponsor related employee volunteering programmes, which was an opportunity missed to highlight these CSR activities, as in the case of Sydney. Additionally, McDonald's failed to capitalise on reporting its Games Makers involvement in its global CSR report for 2012/2013 (McDonald's, 2014), which is somewhat surprising given the global nature of the Olympics as a high profile mega-event.

\section{Legacy}

Given during the legacy phase of Holmes et al.'s (2015) timeline, legacy plans should be put into action and monitored, the ensuing section highlights to what extent corporates were involved in generating a volunteering legacy for the Sydney 2000 and London 2012 Olympic Games. 
In relation to Sydney, there was acknowledgement that the Olympic Games had changed people's perceptions about volunteering, including recognition of corporate engagement in volunteering:

\footnotetext{
"The future of volunteering lies within the corporate sector. A number of our corporate partners embraced our Volunteer Programme - either with direct funding and/or by harnessing their employees and providing them as Games volunteers." (Brettell, 2001, p. 42).
}

As an emerging practice, employee volunteering was recognised as a legacy of the 2000 Games:

"So we now have considerably larger numbers of companies who are engaged in supporting and creating and having activities in volunteering through their companies. So in that respect the legacy has been very good". [R26]

"If there was something solid that IOC could do then it would be to do what Sydney did in ensuring that the partnering of organisations embedded a corporate volunteering programme. That was almost a requirement". [R25]

In contrast, the issue of sponsorship was more of a focus for discussion amongst the London 2012 respondents:

"We would really like it if the IOC took a CSR responsibility approach to this and said to all the top sponsors, one percent of your contribution will go towards legacy stuff. 
That might be quite powerful, because it would guarantee some money. And then you could leverage even more, because you could say to governments, if you want a volunteering legacy for this, there's going to be X million from our sponsor pool, but you've got to match it". [R15]

I'm sure a lot of those Olympic partners would be interested in legacy. So almost even if there was a forum to talk about these are the sorts of things that we think that we could achieve out of this legacy... and give them first refusal ...might be quite a good way to do it and to attract more money. [R10]

Using the example of the Games Makers sponsor, McDonald's:

"You could possibly argue that if you'd gone to McDonald's and said actually you're gonna get two bites of the cherry right? You're gonna have your name stamped all over the Games Makers programme and if you fund us a little bit more money for the next five years after the Games are over, they might be quite interested in that." [R11]

As detailed in the findings related to the Planning phase, across both Games, there was criticism of the lack of funding and necessary structures in place to facilitate volunteering legacies. In the case of the London Games, this criticism came in light of a dedicated volunteering legacy body, Join In, being established post-event.

Established with corporate funding from BT and launched in May 2012, Join In aimed to encourage London 2012 volunteers (now open to everyone) into longer-term volunteering with local sports clubs. However, the Join In programme was criticised as having "begun too 
late to have maximum impact" (House of Lords, 2013, p. 17), with comment that any organisation charged with carrying forward London's volunteering legacy should have been established well in advance of the Games.

Perhaps with greater reach and deeper engagement into the voluntary sector, is the counter example of the Team London Ambassadors programme. Another volunteering legacy of the London 2012 Games, it was established by the Mayor of London in the lead up to the 2012 Olympics, with 8,000 volunteers located at airports and tourist centres to welcome visitors during the Games (DCMS, 2012).

Overall, the case study findings suggest that Team London had a broader focus than Join In's remit of sports volunteering and had been active in engaging with the voluntary and corporate sector:

\footnotetext{
"I think they've nevertheless done some interesting work more generally in terms of taking volunteering forward in London, making connections with companies in the capital, encouraging their staff to volunteer, linking in with programmes to engage young people out of work and volunteering as a way of building up their employability skills. So I think there is some quite good stuff that the London team could be proud of in terms of the legacy". [R6]
}

Team London's programmes have continued post-Games and they have progressively introduced new volunteering initiatives including a range of employee volunteering programmes, from employee secondments, to group and individual employee volunteering opportunities. As the following quote from their website attests: 
"Team London has been growing the capital's volunteering movement and we could not have done this without the help of business. Many organisations in London are already doing amazing work with our communities. We want to help you to do even more" (GLA, 2017).

\section{Discussion}

Based on the findings of this study, we revisit Holmes et al.'s (2015) sustainable event legacy timeline and extend its focus to embedding corporate engagement across the event cycle (see Figure 1). In a first, linking CSR initiatives to legacy planning, the extended model illustrates best practice regarding the involvement of corporates as a key stakeholder group in generating volunteering legacies through the conduct of their event sponsorship and employee volunteering CSR initiatives. In the bid phase, a clear legacy vision for volunteering involving corporate engagement should be articulated and commitments secured based on the long-term nature of corporate sponsor relations associated with the Games. During the planning phase, corporates can be engaged on Olympic volunteer advisory groups and through pre-event volunteering programmes leading up to promoting employee volunteering during Games time. In the transition phase, focus moves to corporate engagement in post-Games initiatives and reporting, and continued involvement with legacy bodies to facilitate longer-term legacies. Figure 1 maps the performance of Sydney 2000 and London 2012 relative to these best practice guidelines thereby highlighting the realised, missed and potential role of corporates as a key stakeholder group involved in the generation of volunteering legacies. 
Additionally, by integrating event sponsorship and employee volunteering in the one framework and studying them for the first time together as CSR initiatives relative to the sporting event context, the case study findings suggest that there was tentative evidence of corporate engagement for both the Sydney 2000 and London 2012 Olympic Games in respect of these initiatives across event planning cycle. For the most part, the application of CSR initiatives was fragmented and primarily focused on the immediate planning and delivery stages of the event cycle, supporting Dowling et al's. (2013) contention that sports and CSR partnership efforts are predominantly scheduled in the lead up to mega-events. Relative to the best practice timeline presented in Figure 1, there were ample opportunities for further engagement to foster a sustainable legacy for volunteering in the host cities over time.

Based on these findings, evidence of corporate involvement as a key stakeholder group in legacy management and realisation remains tentative. The extent of legacy to arise from McDonald's involvement in the 2012 Games, for example, is uncertain given it did not continue beyond the event phase. Without this continuity, the good work done at the planning and event phases may not continue to legacy realisation. Additionally, their involvement remained largely unknown outside of the UK, which represented a missed opportunity given the global nature of their business and their significant sponsor investment and campaign efforts to promote Games Maker volunteering. In not capitalising on this opportunity, McDonald's likely did not reap the full benefits research has shown to flow from CSR initiatives related to sponsorship and employee volunteering including favourable social responsibility assessments by employees (Bhattacharya et al., 2009; Edwards, 2016) and customers alike (Plewa et al., 2015; Close Scheinbaum \& Lacey, 2015). 
Nevertheless, both Games demonstrated innovation in terms of corporate involvement. Given employee volunteering was viewed as an emerging trend in the volunteer space until relatively recently (Haski-Leventhal et al., 2009), the Sydney Games were at the forefront of introducing this practice to the Olympics. By London 2012, corporate involvement in the Games appears to be accepted practice (Kim, 2013). London demonstrates an emergent model for corporate involvement as a CSR initiative both in the delivery of Olympic volunteering programmes and extending into the legacy phase of the sustainable event timeline. Join In and Team London, though not established until the transition phase, represent a leap forward in volunteer legacy management. This suggests that expanding the model to create a dedicated body, separate from the OCOG, with remit for legacy planning and delivery, working from bid to legacy phase alongside the OCOG, with its own dedicated budget, would seem the way forward to overcome the challenges inherent in current legacy planning and delivery (Cashman, 2006; Dickson et al., 2011). If such a legacy focused body were to come into play, then corporates could pursue CSR activities with both the OCOG and the body, in sponsoring and providing employee talent to underpin the success of the Olympics across all phases of the event cycle.

\section{Conclusion}

This study contributes to the literature on CSR and sports events by examining to what extent the CSR initiatives of corporate sponsorship and employee volunteering are currently embedded within the Olympic planning cycle. While the literature on event legacies has grown, the role of corporates in contributing to these as part of their CSR plans has not been explored, neither has their actual and potential contribution as a key stakeholder group involved in legacy management. The two case studies of the Sydney 2000 and London 2012 
Olympic Games have enabled a framework to be developed outlining where these initiatives can contribute towards a sustainable legacy for volunteering, pre- and post-event addressing calls for such an extended perspective (Dickson et al., 2011).

While the increasing corporatisation of the Olympics has been criticised (Giannoulakis \& Stotlar, 2006), through the lens of CSR, we would argue corporates have much to contribute to generating volunteer legacies across the event planning cycle. The opportunities for engaging this stakeholder group in Olympic legacies are greater where the voluntary sector in the host city is under-resourced (Davis Smith, 2016) and in light of the OCOG disbanding immediately post-event (Benson et al., 2014). For corporates, using their more substantial resources, there are opportunities to more deeply engage in sustained CSR initiatives such as employee volunteering, which may be viewed as inherently altruistic (Clary \& Snyder, 1999).

Such initiatives could offset potential negative views of the sponsors' products (Batty et al., 2016) and offer a form of meaningful engagement akin to that highlighted in Dowling et al.'s (2013) study, which is harder for competitors to replicate and ambush and faces less consumer skepticism (Plewa \& Quester, 2011). Additionally, in the case of Olympic sponsors, given their multi-year partner agreements exist before and after each iteration of the Games, these sustained relationships have the potential to underpin successful pre- and postGames legacy initiatives. There is scope for such legacy generation efforts to deliver benefits to the corporate long after the actual Games has been and gone (Watt, 2010).

This study extends the literature on mega-event legacies, particularly the noted dearth of research examining various stakeholder roles in relation to legacy management and governance (Leopkey \& Parent, 2012, 2017). From our analysis of how corporates engaged as 
a key stakeholder with both case study Games over the event planning life cycle, both good practice and missed opportunities emerged, with these insights providing guidance for future events, specifically around supporting event legacy fulfilment through corporate involvement. Further research is needed to track longitudinally specific examples of CSR initiatives to confirm whether they lead to enhanced volunteering legacies, either directly through the employees of corporates volunteering elsewhere, or indirectly through sponsor funding, for example, supporting volunteer training, which gives people potentially new to volunteering, the skills and confidence to continuing volunteering post-Games. Additionally, research examining the effects of employee volunteering as a CSR initiative in offsetting negative perceptions of a corporates' products, akin to Batty et al.'s (2016) study of corporate sponsorship, would also prove a worthwhile extension of the current study.

In conclusion, by drawing on data from the two Olympic Games to populate Holmes et al.'s (2015) sustainable legacy timeline, the research reveals valuable opportunities for volunteer legacy planning and delivery through closer engagement with corporates and their CSR initiatives related to sponsorship and employee volunteering. Our findings will enable Olympic hosts to harness the skills and resources of corporates and their employees both during and after the Games to engender a sustainable legacy for volunteering across the event cycle. 


\section{References}

Altin, K., Redford, N., \& Webster, J. (2013). We all make the Games. London: McDonald's.

Auld, C., Cuskelly, G., \& Harrington, M. (2009). Managing volunteers to enhance the legacy potential of major events. Oxfordshire: CABI.

Bashir, M. (2012). An Olympic legacy for all? London 2012 and social exclusion. London: Personal Best.

Basu, K., \& Palazzo, G. (2008). Corporate social responsibility: A process model of sensemaking. Academy of Management Review, 33(1), 122-136.

Batty, R., Cuskelly, G., \& Toohey, K. (2016). Community sport events and CSR sponsorship: Examining the impacts of a public health agenda. Journal of Sport and Social Issues, 40(6), 545-564.

Benson, A., Dickson, T., Terwiel, F., \& Blackman, D. (2014). Training of Vancouver 2010 volunteers: A legacy opportunity? Contemporary Social Science, 9(2), 210-226.

Bhattacharya, C. B., Korschun, D., \& Sen, S. (2009). Strengthening stakeholder-company relationships through mutually beneficial corporate social responsibility initiatives. Journal of Business Ethics, 85, 257-272.

Brettell, D. (2001). The Sydney volunteers. Olympic Review, 42, 37-43.

Carey, M., Mason, D., \& Misener, L. (2011). Social responsibility and the competitive bid process for major sporting events. Journal of Sport and Social Issues, 35(3), 246-263.

Cashman, R. (2006). The bitter-sweet awakening: The legacy of the Sydney 2000 Olympic Games. Sydney: Walla Walla Press.

Cho, J.-H., \& Bairner, A. (2012). The sociocultural legacy of the 1988 Seoul Olympic Games. Leisure Studies, 31(3), 271-289.

Clary, E., \& Snyder, M. (1999), The motivations to volunteer theoretical and practical considerations, Current Directions in Psychological Science, 8(5), 156-59. 
Close Scheinbaum, A., \& Lacey, R. (2015). Event social responsibility: A note to improve outcomes for sponsors and events. Journal of Business Research, 68, 1982-1986.

Coyne, B., \& Coyne, E. (2001). Getting, keeping and caring for unpaid volunteers for professional golf tournament events. Human Resource Development International, 4(2), 199216.

Cunliffe, P. (2012). Sponsoring the Games brings gold for Cadbury. Sunday Express, Retrieved from http://www.express.co.uk/finance/city/334333/Sponsoring-the-Games-bringsgold-for-Cadbury.

Cresswell, J. (2013). Qualitative inquiry and research design: Choosing among five approaches. Thousand Oaks: Sage.

Creswell, J., \& Plano Clark, V. (2007). Designing and conducting mixed methods research. Thousand Oaks: Sage.

Davis Smith, J. (2016). From Games Makers to givers. Retrieved from https://justindavissmith.wordpress.com/2016/08/09/from-games-makers-to-givers/ DCMS (Department of Culture, Media and Sport). (2007). Our promise for 2012: How the UK will benefit from the Olympic Games and Paralympic Games. Retrieved from https://www.gov.uk/government/uploads/system/uploads/attachment_data/file/77719/Ourpro mise2012.pdf

DCMS (Department of Culture, Media and Sport). (2008). Before, during and after: Making the most of the London 2012 Games. London: DCMS.

DCMS (Department of Culture, Media and Sport). (2010). Plans for the legacy from the 2012 Olympic and Paralympic Games. London: DCMS.

DCMS (Department of Culture, Media and Sport). (2012). Beyond 2012: The London legacy story. London: DCMS. 
Dickson, T., Benson, A., \& Blackman, D. (2011). Developing a framework for evaluating Olympic and Paralympic legacies. Journal of Sport \& Tourism, 16(4), 285-302.

Doherty, A. (2009). The volunteer legacy of a major sport event. Journal of Policy Research in Tourism, Leisure and Events, 1(3), 185-207.

Dowling, M., Robinson, L., \& Washington, M. (2013). Taking advantage of the London 2012 Olympic Games: Corporate social responsibility through sport partnerships. European Sport Management Quarterly, 13(3), 269-292.

Edwards, M. (2016). The Olympic effect: Employee reactions to their employer's sponsorship of a high-profile global sporting event. Human Resource Management, 55(4), 721-740.

Elstad, B. (1996). Volunteer perception of learning and satisfaction in a mega-event: The case of the XVII Olympic Winter Games in Lillehammer. Festival Management and Event Tourism, 4(3-4), 75-83.

Experian. (2006). Employment and skills for the 2012 Games: Research and evidence. London: Experian.

Flyvbjerg, B., \& Stewart, A. (2012). Olympic proportions: Cost and cost-overrun at the Olympics 1960-2012 (Said Business School Working Papers). Oxford: University of Oxford. Giannoulakis, C., \& Stotlar, D. (2006). Evolution of Olympic sponsorship and its impact on the Olympic movement. In Proceedings of International Symposium for Olympic Research. Lausanne: IOC.

GLA (Greater London Authority). (2017). Working with London's business community. GLA. Retrieved from https://www.london.gov.uk/what-we-do/volunteering/working-londonsbusiness-community Haski-Leventhal, D., Meijs, L., \& Hustinx, L. (2009). The third-party model: Enhancing volunteering through governments, corporations and educational institutes. Journal of Social Policy, 39(1), 139-158. 
Holmes, K., Hughes, M., Mair, J., \& Carlsen, J. (2015). Events and Sustainability. Abingdon: Routledge.

House of Lords Select Committee on Olympic and Paralympic Legacy. (2013). Keeping the flame alive: The Olympic and Paralympic legacy. London: House of Lords.

IOC (International Olympic Committee). (1992). Manual for cities bidding for the Olympic Games. Lausanne: IOC.

IOC (International Olympic Committee). (2001). Sydney 2000 marketing report: Games of the XXVII Olympiad. Lausanne: IOC.

IOC (International Olympic Committee). (2004). 2012 Candidature procedure and questionnaire: Games of the XXX Olympiad in 2012. Lausanne: IOC.

IOC (International Olympic Committee). (2005). Report of the IOC Evaluation Commission for the Games of the XXX Olympiad in 2012. Lausanne: IOC.

IOC (International Olympic Committee). (2007). Olympic charter. Lausanne: IOC.

IOC (International Olympic Committee). (2012). Olympic legacy. Lausanne: IOC.

Kim, H.-D. (2013). The 2012 London Olympics: Commercial partners, environmental sustainability, corporate social responsibility and outlining the implications. The International Journal of the History of Sport, 30(18), 2197-2208.

King, N. (2004). Using templates in the thematic analysis of text. In C. Cassell \& G. Symon (Eds.). Essential guide to qualitative methods in organizational research (pp. 11-22). London: Sage Publications.

Kotler, P., \& Lee, N. (2004). Corporate social responsibility: Doing the most good for your company and your cause. New Jersey: John Wiley and Sons.

Kumar, A. (2012). Volunteer motivation v. sponsorship activation. Retrieved from http://www.athleticscommunity.org/blog/detail/110/ 
Lacey, R., Close, A., \& Finney, R. (2010). The pivotal roles of product knowledge and corporate social responsibility in event sponsorship effectiveness. Journal of Business Research, 63, 1222-1228.

Leopkey, B., \& Parent, M. M. (2012). Olympic Games legacy: From general benefits to sustainable long-term legacy. International Journal of the History of Sport, 29(6), 924-943. Leopkey, B. \& Parent, M. M. (2017). The governance of Olympic legacy: Process, actors and mechanisms. Leisure Studies, 36(3), 438-451.

Lincoln, Y., \& Guba, E. (1985). Naturalistic inquiry. Newbury Park: Sage Publications.

LOCOG (Organising Committee of the London Olympic and Paralympic Games). (2011).

Games Maker workbook. London: LOCOG.

LOCOG (Organising Committee of the London Olympic and Paralympic Games). (2012a).

Ready, Progress report for the 124th IOC session, London, 21 July. London: London

Organising Committee of the Olympic and Paralympic Games (LOCOG).

LOCOG (Organising Committee of the London Olympic and Paralympic Games). (2012b).

London 2012 post-Games sustainability report: A legacy of change. London: LOCOG.

LOCOG (Organising Committee of the London Olympic and Paralympic Games). (2012c).

London 2012 Olympic and Paralympic Games: The official commemorative book. London:

London Organising Committee of the Olympic and Paralympic Games (LOCOG).

LOCOG (Organising Committee of the London Olympic and Paralympic Games). (2013).

London 2012 Olympic Games official report, volume 3. London: LOCOG.

London 2012 Ltd. (2004). London 2012 candidate city, candidate file, volume 1. London:

London 2012 Ltd.

McDonald's (2014). Our journey together. For good. McDonald's corporate social responsibility \& sustainability report 2012-2013. Illinois: McDonald's. 
Minnaert, L. (2012). An Olympic legacy for all? The non-infrastructural outcomes of the Olympic Games for socially excluded groups (Atlanta 1996-Beijing 2008). Tourism Management, 33(2), 361-370.

Musick, M., \& Wilson, J. (2007). Volunteers: A social profile. Bloomington: Indiana University Press.

Muthuri. J., Matten, D., \& Moon, J. (2009). Employee volunteering and social capital: Contributions to corporate social responsibility. British Journal of Management, 20, 75-89. Nakamura, H., \& Suzuki, N. (2017). Reinterpreting Olympic legacies: the emergent process of long-term post-event strategic planning of Hakuba after the 1998 Nagano Winter Games. International Journal of Sport Policy and Politics, 9(2), 311-329.

Nichols, G. (2012). Volunteering for the Games. In V. Girginov \& B. Majumdar (Eds.), Handbook of the London 2012 Olympic and Paralympic Games (pp. 215-224). London: Taylor and Francis.

Nichols, G., \& Ralston, R. (2011). Social inclusion through volunteering: The legacy potential of the 2012 Olympic Games. Sociology, 45(5), 900-914.

Noy, C. (2008). Sampling knowledge: The hermeneutics of snowball sampling in qualitative research. International Journal of Social Research Methodology, 11(4), 327-344.

Plewa, C., Conduit, J., Quester, P., \& Johnson, C. (2015). The impact of corporate volunteering on CSR image: A consumer perspective. Journal of Business Ethics, 127, 643659.

Plewa, C., Carrillat, F. A., Mazodier, M., \& Quester, P. G. (2016). Which sport sponsorships most impact sponsor CSR image? European Journal of Marketing, 50(5/6), 796-815. Plewa, C., \& Quester, P. (2011). Sponsorship and CSR: Is there a link? A conceptual framework. International Journal of Sports Marketing \& Sponsorship, 12(4), 22-38. 
Preuss, H. (2007). The conceptualisation and measurement of mega sport event legacies. Journal of Sport \& Tourism, 12(3-4), 207-228.

Ritchie, J. R. B. (2000). Turning 16 days into 16 years through Olympic legacies. Event Management, 6, 155-165.

Sen, S., \& Bhattacharya, C. B. (2001). Does doing good always lead to doing better? Consumer reactions to corporate social responsibility. Journal of Marketing Research, 38(2), $225-243$

Sheth, H., \& Babiak, K. (2009). Beyond the game: Perceptions and practices of corporate social responsibility in the professional sport industry. Journal of Business Ethics, 91, 433450.

SOCOG (Organising Committee of the Sydney Olympic and Paralympic Games). (2001). Official report of the XXVII Olympiad Volume One: Preparing for the Games. Sydney: SOCOG.

Tashakkori, A., \& Teddlie, C. (2003). The handbook of mixed methods in social and behavioral research. Thousand Oaks: Sage Publications.

Tomlinson, D. (2012, July 19). How Kraft Foods is inspiring employees through the opportunity of London 2012. Retrieved from http://www.hrmagazine.co.uk/articledetails/how-kraft-foods-is-inspiring-employees-through-the-opportunity-of-london-2012 Uhrich, S., Koenigstorfer, J., \& Groeppel-Klein, A. (2014). Leveraging sponsorship with corporate social responsibility. Journal of Business Research, 67, 2023-2029.

Walker, M., Heere, B., Parent, M. M., \& Drane, D. (2010). Social responsibility and the Olympic Games: The mediating role of consumer attributions. Journal of Business Ethics, 95, $659-680$.

Watt, K. (2010). The future of sponsorship integrated with CSR/CSI strategy. Journal of Sponsorship, 3(3), 220-227. 
Westpac. (2002). A fresh perspective, our first social impact report. Sydney: Westpac.

Yin, R. (2014). Case study research: Design and methods (5 ${ }^{\text {th }}$ edn.). Thousand Oaks: Sage Publications. 
Table

Table 1 Respondent profile

\begin{tabular}{|c|c|c|}
\hline & $\begin{array}{l}\text { Role in relation to Sydney } 2000 \\
\text { Olympic Games }\end{array}$ & $\begin{array}{l}\text { Role in relation to London } 2000 \text { Olympic } \\
\text { Games and/or legacy period }\end{array}$ \\
\hline $\begin{array}{l}\text { Organising } \\
\text { Committee } \\
\text { (roles not listed to } \\
\text { maintain } \\
\text { confidentiality) }\end{array}$ & $\begin{array}{l}\text { R17-SOCOG } \\
\text { R18 - SOCOG }\end{array}$ & R13 - LOCOG \\
\hline $\begin{array}{l}\text { Policy-makers, } \\
\text { government } \\
\text { representatives and } \\
\text { official legacy bodies }\end{array}$ & & $\begin{array}{l}\text { R2 - Legacy Body } \\
\text { R3 - Legacy Body } \\
\text { R9 - Government Legacy Unit } \\
\text { R10 - Local Government Legacy Body } \\
\text { R11 - Local Government Legacy Body } \\
\text { R15 - Legacy Body }\end{array}$ \\
\hline $\begin{array}{l}\text { Sport governing } \\
\text { bodies and } \\
\text { community } \\
\text { organisations } \\
\end{array}$ & $\begin{array}{l}\text { R22 - Non-profit organisation } \\
\text { R27 - Non-profit organisation }\end{array}$ & $\begin{array}{l}\text { R1 - National Sports Organisation } \\
\text { R14 - National Sports Organisation } \\
\text { R16 - National Sports Organisation }\end{array}$ \\
\hline $\begin{array}{l}\text { Peak volunteering } \\
\text { bodies and volunteer } \\
\text { resource centres }\end{array}$ & $\begin{array}{l}\text { R19 - Peak volunteering body } \\
\text { R24 - Peak volunteering body } \\
\text { R25 - Peak volunteering body } \\
\text { R26 - Peak volunteering body }\end{array}$ & $\begin{array}{l}\text { R4 - Volunteer Resource Centre } \\
\text { R5 - Volunteer Resource Centre } \\
\text { R6 - Peak volunteering body } \\
\text { R7 - Volunteer Resource Centre }\end{array}$ \\
\hline $\begin{array}{l}\text { Others (e.g., } \\
\text { volunteers, university } \\
\text { representative, } \\
\text { researchers) }\end{array}$ & $\begin{array}{l}\text { R20 - University representative } \\
\text { R21 - Olympic volunteer } \\
\text { R23 - Pioneer volunteer }\end{array}$ & $\begin{array}{l}\text { R8 - Researcher } \\
\text { R12 - University representative }\end{array}$ \\
\hline
\end{tabular}




\begin{tabular}{|c|c|c|c|c|c|}
\hline \multicolumn{6}{|c|}{ igure } \\
\hline & Bid document prepared & Event planning phase & The event & Transition phase & Legacy phase \\
\hline 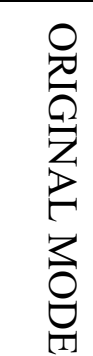 & $\begin{array}{l}\text { Legacy vision and post- } \\
\text { event plans for site and } \\
\text { venue developed } \\
\text { - Feasibility studies conducted }\end{array}$ & $\begin{array}{l}\text { - Planning for legacy takes } \\
\text { place during this phase } \\
\text { - Contracts for post-event } \\
\text { programmes and venues put } \\
\text { in place } \\
\text { - Funds for legacy must be } \\
\text { spent or committed now }\end{array}$ & $\begin{array}{ll}\text { The legacy is } \\
\text { temporarily on hold } \\
\text { while the focus is on the } \\
\text { staging of the event }\end{array}$ & $\begin{array}{l}\text { - In the immediate aftermath } \\
\text { of the event, the legacy } \\
\text { plans begin to be put into } \\
\text { process but it will take time } \\
\text { to yield results. } \\
\text { - A media communication } \\
\text { plan is needed to prevent } \\
\text { premature negative press }\end{array}$ & $\begin{array}{l}\text { - The legacy plan is } \\
\text { put into action } \\
\text { - Ongoing research } \\
\text { and monitoring of } \\
\text { event impacts }\end{array}$ \\
\hline 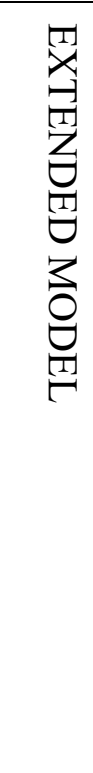 & $\begin{array}{l}\text { Articulate a clear vision and } \\
\text { post-event plans for } \\
\text { volunteering legacies, } \\
\text { including identification of } \\
\text { corporate commitments } \\
\text { required for legacy } \\
\text { realisation } \\
\text { Sydney and London - no } \\
\text { explicit focus on volunteer } \\
\text { legacy }\end{array}$ & $\begin{array}{l}\text { - Corporate engagement in the } \\
\text { 'pre-event volunteer } \\
\text { programme' as a 'pre-event' } \\
\text { volunteering legacy } \\
\text { London- some evidence } \\
\text { Corporate involvement on } \\
\text { the volunteering advisory } \\
\text { group to the OCOG and } \\
\text { legacy body } \\
\text { Sydney - some evidence } \\
\text { Planning for corporate } \\
\text { sponsorship of the Games } \\
\text { time volunteer programme } \\
\text { London - achieved } \\
\text { - Sponsor allocations to the } \\
\text { planned volunteering legacy } \\
\text { programme } \\
\text { Sydney and London - no } \\
\text { evidence }\end{array}$ & $\begin{array}{l}\text { Corporates facilitate } \\
\text { and promote Games } \\
\text { time employee } \\
\text { volunteering efforts } \\
\text { Sydney and London- } \\
\text { some evidence } \\
\text { Corporates leverage off } \\
\text { (promote) any } \\
\text { involvement with } \\
\text { Olympic volunteering } \\
\text { London- some } \\
\text { evidence }\end{array}$ & $\begin{array}{l}\text { Corporates promote } \\
\text { continued employee } \\
\text { volunteering post-Games } \\
\text { Sydney - some evidence } \\
\text { Corporates and the OCOG } \\
\text { report on the outcomes of } \\
\text { any CSR initiatives related } \\
\text { to the Olympic volunteering } \\
\text { programme } \\
\text { Sydney - some evidence }\end{array}$ & $\begin{array}{l}\text { Corporates work } \\
\text { with the legacy } \\
\text { body to deliver } \\
\text { upon legacy plans } \\
\text { London-some } \\
\text { evidence (Team } \\
\text { London) }\end{array}$ \\
\hline
\end{tabular}

Figure 1 Original sustainable legacy timeline (Holmes et al., 2015) and extended version for best practice corporate engagement 